\title{
OCCUPATIONAL STRESS, SENSE OF COHERENCE, COPING, BURNOUT AND WORK engagement of Registered nURSes in South Africa
}

\section{Authors:}

Jacoba J. van der Colff ${ }^{1}$

Sebastiaan Rothmann ${ }^{1}$

\section{Affiliations:}

${ }^{1}$ School of Behavioural

Sciences, Vanderbijlpark

North-West University,

South Africa

\section{Correspondence to:}

Sebastiaan Rothmann

e-mail:

ian@ianrothmann.com

\section{Postal address}

PO Box 8660, Swakopmund, Namibia

\section{Keywords:}

distress; eustress; psychological strengths; well-being; wellness

\section{Dates:}

Received: 08 Apr. 2008 Accepted: 26 Sept. 2008 Published: 09 Apr. 2009

How to cite this article: Van der Colff, J.J., \& Rothmann, S. (2009). Occupational stress, sense of coherence, coping, burnout and work engagement of registered nurses in South Africa. SA Journal of Industrial Psychology/SA Tydskrif vir Bedryfsielkunde, 35(1), Art. \#423, 10 pages. DOI: 10.4102/sajip.v35i1.423

This article is available at: http://www.sajip.co.za

(C) 2009. The Authors. Licensee: OpenJournals Publishing. This work is licensed under the Creative Commons Attribution License.

\section{ABSTRACT}

The aim of this study was to assess the relationship between the occupational stress, sense of coherence, coping, burnout and work engagement of registered nurses in South Africa. A crosssectional survey design was used. The study population consisted of 818 registered nurses. The Nursing Stress Inventory, the Orientation to Life Questionnaire, the COPE, the Maslach Burnout Inventory-Human Services Survey, and the Utrecht Work Engagement Scale were administered. The results show that the experience of depletion of emotional resources and feelings of depersonalisation by registered nurses were associated with stress due to job demands and a lack of organisational support, focus on and ventilation of emotions as a coping strategy, and a weak sense of coherence. Work engagement was predicted by a strong sense of coherence and approachcoping strategies.

\section{INTRODUCTION}

A stable and productive health service is of vital importance to any country. The health service would include the nursing profession, which comprises by far the greatest component of this service sector. Nursing is seen as a stressful and emotionally demanding profession (Carson, Bartlett \& Croucher 1991; Coffey \& Coleman, 2001; Fagin, Brown, Bartlett, Leary \& Carson, 1995; Schaufeli \& Janczur, 1994; Snellgrove, 1998), which makes nurses exceptionally susceptible to burnout.

Occupational stress has several negative effects, such as impaired performance and effectiveness, reduction in productivity, diminishing levels of customer service, health problems, absenteeism, turnover, industrial accidents, alcohol and drug usage, purposefully destructive behaviours, e.g. spreading of rumours and stealing (Happel, Pinikahana \& Martin, 2003; Perrewé, 1991; Quick, Quick, Nelson \& Hurrell, 1997; Wright \& Smye, 1996), and even suicide (McGrath, Reid \& Boore, 2003). The potential direct and indirect costs associated with various stress-related consequences command more than just adequate attention from the manager of any business. Stress is seen by Cherniss (1995) as the main contributing factor to burnout.

Stress is but one aspect that influences a person's well-being negatively. Studies have confirmed that one's sense of coherence is an important component of one's health and well-being (Antonovsky, 1987, 1993). Sense of coherence has been defined as a relatively stable dispositional orientation that is represented by the concepts of comprehensibility, manageability and meaningfulness (Antonovsky, 1987). A strong sense of coherence is related to general well-being (Feldt, 1997). Individuals with high levels of burnout would be expected to demonstrate lower levels of a sense of coherence. Specifically, the manageability component of a sense of coherence has been proven to be related to the exhaustion component of burnout (Rothmann \& Malan, 2003).

According to Antonovsky (1987), a strong sense of coherence is not a particular coping style, and the stressors life imposes are many and varied. To adopt one pattern of coping consistently is precisely to fail to respond to the nature of the stressor, and hence to decrease the chances of successful coping. A person with a strong sense of coherence selects the particular coping strategy that seems most appropriate to deal with the stressor being confronted. Subsequently, the availability of a wide repertoire of coping strategies and flexibility in choice at any given time are crucial (Antonovsky, 1987; Feldt, 1997). The stronger the sense of coherence a person has, the better his/her ability to employ cognitive, affective and instrumental strategies that are likely to improve coping and, subsequently, well-being.

Coping refers to the perceptual, cognitive or behavioural responses used to manage, avoid or control situations that could be regarded as difficult (Folkman \& Lazarus, 1984; Moos, 1994; Zeidner \& Endler, 1996). Lazarus and Folkman (1984) initially identified two coping strategies, namely problem-focused or active coping and emotion-focused or passive coping. Problem-focused strategies include strategies such as defining the problem, generating and weighing alternative solutions, and following a plan of action, whereas emotion-focused strategies include processes such as avoidance, denial, seeking emotional support, and positive appraisal (Folkman \& Lazarus, 1984).

According to Alsoofi, Al-Heeti and Alwashli (2000), burnout and coping strategies seem to be related significantly. The use of withdrawal or avoidance (passive) coping strategies is associated with high levels of burnout, while low burnout levels are associated with constructive or active (problem-focused) coping strategies (Schaufeli \& Enzmann, 1998).

Although burnout can occur in any occupation, nursing is considered as being inherently stressful and an above-average risk group regarding work stress (Demerouti, Bakker, Nachreiner \& Schaufeli, 2000; Levert, Lucas \& Ortlepp, 2000; According to Schaufeli and Janczur (1994), nurses' tasks are demanding because they work with the suffering, grief and death of people. Although occupational stressors that give rise to stress and, ultimately, to burnout are a reality in the nursing profession, there is also another (positive) side to the coin, namely being dedicated to and immersed in one's work, which is referred to in the literature as engagement (Schaufeli, Salanova, Gonzáles-Romá \& Bakker, 2002). Engaged employees 
see themselves as competent in dealing with the demands of their job. They are energetic and have a sense of effective connection with their work activities.

The impact of burnout - regarded as the opposite concept of engagement - on the quality of care in the nursing profession should not be underestimated. The prevalence rates of occupational stress are rising continuously in most industrialised countries, as indicated by the increase in stressrelated absenteeism. The literature also reports an increase in the number of individuals who receive disability grants due to mental (possibly stress related) disorders (Schaufeli \& Enzmann, 1998). In the light of these facts, the importance of identifying personality traits and job stressors related to burnout and engagement is indisputably of great importance to improve the standard of health services and care in the nursing profession. The negative impact of burnout does not apply only to the individual, but also - and in particular - to government and private organisations.

The aim of this study was to investigate the relationship between the occupational stress, sense of coherence, coping, burnout and work engagement of registered nurses in South Africa.

\section{Occupational stress}

Various models have been developed to understand occupational stress, such as the Person-Environment Fit Model (French, Kaplan \& Harrison, 1982) and the Demand-Control Model of Karasek (Fox, Dwyer \& Ganster, 1993). The former approach views psychological and physical stress as being the result of an incongruent person-environment fit, while the Demand-Control Model looks at the interaction between the demands of the situation and the individual's decisional freedom in terms of meeting the job requirements. Although these models influenced a considerable body of research on stress, they focus on the general demands of the job and the skills and abilities of the incumbent, not taking into account the specific pressures and the role of individual differences in personality and coping resources (Spielberger \& Vagg, 1999).

On the basis of the Demand-Control Model of Karasek (Fox et al., 1993) and research results from the Maslach Burnout Inventory (MBI), Maslach and Jackson (1986) postulated that the presence of particular demands (i.e. work overload and personal conflicts) and the absence of particular resources (i.e. control coping, social support, autonomy and participation) would lead to the prevalence of burnout, resulting in other expected negative outcomes, such as physical illness, turnover, absenteeism, and diminished organisational commitment.

Cavanagh (1997) and Cocco, Gatti, De Mendonça Lima and Camus (2003) divide stressors in the nursing profession into three categories, namely personal (or intrapersonal), interpersonal and work environment or organisational stressors. Personal stressors include an inability to manage home, work and sometimes also study responsibilities and an inadequate preparation of personnel for the demanding tasks of nursing. Interpersonal stressors reflect on relationships with doctors, supervisors, other senior personnel and colleagues (Basson \& Van der Merwe, 1994). Work environment stressors include modern technology that is, in essence, inhumane and depersonalised (Cavanagh, 1997; Lewis, 1988); a high work load and long working hours that do not contribute to a personal and social life (Basson \& Van der Merwe, 1994; Cavanagh, 1997); procedures that endanger nurses' lives; caring for and especially dealing with pain, suffering and dying; the strain of being exposed to making mistakes and managing demanding responsibilities (Cavanagh, 1997); a lack of autonomy (Schaufeli \& Enzmann, 1998); role conflict and role ambiguity (Levert et al., 2000) and under-staffing (Erasmus, Poggenpoel \& Gmeiner, 1998; Kilfedder, Power \& Wells, 2001).

\section{Sense of coherence}

Antonovsky (1987) predicted that sense of coherence, defined as a relatively stable dispositional orientation, might cause employees with a strong sense of coherence to experience less job stress. A strong sense of coherence might help employees understand stressors and regard them as manageable and meaningful. A weak sense of coherence might therefore lead to job stress, which in turn could lead to burnout. Each person's sense of coherence, or sense of well-being, requires certain inherent prerequisites for coping successfully, which are represented by the concepts of comprehensibility, manageability and meaningfulness (Antonovsky, 1987). Rothmann, Jackson and Kruger (2003) found that sense of coherence contributes to the professional efficacy of employees. Amirkhan and Greaves (2003) showed that a strong sense of coherence impacts on perception so that individuals with a strong orientation are likely to view a greater number of events as having coherence. This perceptual process seems to be subtle: it influences individuals' perceptions of stressful events, but it does so without their conscious awareness.

\section{Coping}

The literature on stress research is frequently linked to coping mechanisms. According to Bhagat et al. (2001), the level of stress experienced and the extent to which adverse psychological and physiological effects of stress occur depend on how well the individual utilises coping strategies in the organisational setting.

Coping can be defined as the cognitive and behavioural efforts that individuals make to manage situations appraised as potentially harmful or stressful (Kleinke, 1991; McElfatrick et al., 2000). According to Fleishman (1984), coping could refer to either strategies or results. As a strategy, coping refers to the different methods that individuals employ to manage their specific circumstances, while coping as a result refers to the eventual outcomes of the chosen strategy for the individual. Tobin, Holroyd, Reynolds and Wigal (1989) distinguished between approach-oriented and avoidance-oriented processes in coping strategies. Consequently, coping strategies could be viewed from an active as well as a passive approach, where movement towards a stressor (i.e. active coping) or away from the stressor (i.e. passive coping) is taken as broad strategies.

According to Lazarus (1991), the individual processing or appraisal of a stressful event takes place on two levels. In primary appraisal, significance is attached to the situation to determine whether or not the particular situation poses a potential or actual threat to the individual's well-being. In the secondary appraisal process, the perceived ability of coping resources to deal with the event is evaluated. These appraisal processes can be viewed as interdependent, influencing each other and shaping the nature of any encounter on an individual level (Folkman \& Lazarus, 1984). Consequently, coping is regarded as a process whereby the individual interacts with his/her environment in order to comprehend what people actually think and do in a stressful encounter (Holroyd \& Lazarus, 1982).

\section{Burnout}

Burnout has long been a proven reality in the nursing profession (Glass, McKnight \& Valdimarsdottir, 1993; Lewis, 1988; McKnight \& Glass, 1995; Schaufeli \& Janczur, 1994; Tarolli-Jager, 1994), with symptoms such as low energy levels, feelings of a lack of control, helplessness, low motivational levels, negative attitudes towards work, self and others, emotional exhaustion, absenteeism and turnover, performance deficits and substance abuse (Glass et al., 1993).

Maslach, Schaufeli and Leiter (2001) describe burnout as a syndrome consisting of three key dimensions, namely feelings 
of emotional exhaustion, depersonalisation and reduced personal accomplishment. Emotional exhaustion, representing the individual stress dimension of burnout, refers to feelings of depleted physical and emotional resources and prompts actions in workers to distance themselves emotionally and cognitively from their work, presumably as a way to cope with work overload. Depersonalisation entails negative and cynical attitudes or excessively detached responses towards the recipients of service and care (e.g. patients), reducing the recipient to an impersonal object. These two dimensions are generally considered to comprise the core symptoms of burnout (Demerouti et al., 2000). The third dimension, lack of personal accomplishment, represents the self-evaluation dimension of burnout and refers to feelings of insufficiency (Schaufeli \& Buunk, 1996), incompetence, lack of achievement and unproductiveness (Maslach et al., 2001).

\section{Work engagement}

Empirical studies have revealed that some employees, regardless of high job demands and long working hours, do not develop burnout, but seem to find pleasure in hard work and dealing with job demands (Schaufeli \& Bakker, 2001).

Schaufeli et al. (2002) argue that the simultaneous empirical investigation of burnout and engagement would be impossible with one instrument. Based on a theoretical analysis, burnout and engagement are conceptually related to each other, resulting in two work-related dimensions of well-being, namely (1) activation, ranging from exhaustion to vigour, and (2) identification, ranging from cynicism to dedication (Schaufeli \& Bakker, 2001). Personal accomplishment and absorption were also included in the burnout and engagement constructs respectively, but not in an antithetical manner. It was argued that personal accomplishment was added only afterwards in the development of the Maslach Burnout Inventory (MBI), when a third factor was discovered during a factor analysis of a preliminary version of the MBI (Maslach, 1993).

Engagement is therefore defined as a positive, fulfilling, workrelated state of mind that is characterised by three dimensions, namely vigour, dedication and absorption (Schaufeli et al., 2002). Vigour refers to having high energy levels, resilience regarding work activities, investing effort in one's work and persistence in difficult circumstances. Dedication includes a sense of significance, enthusiasm, inspiration, pride and challenge, while absorption is characterised by full concentration on and engrossment in one's work, and finding it difficult to detach oneself from work (Schaufeli et al., 2002). Absorption comes close to the concept of 'flow', which is characterised by an optimal state in which focused attention, a clear mind, unison of body and mind, effortless concentration, complete control, loss of self-consciousness, time distortion and intrinsic enjoyment are experienced (Csikszentmihalyi, 1997). Engagement is theoretically viewed as the opposite end of the continuum from burnout that cannot be effectively measured by the Maslach Burnout Inventory (MBI), but is measured by its own survey, the Utrecht Work Engagement Scale (UWES) (Schaufeli et al., 2002).

A study done by Mostert and Rothmann (2006) revealed that work engagement was best predicted by conscientiousness, emotional stability, and low stress due to job demands. People with a strong sense of coherence were also found to experience more work engagement (Naudé \& Rothmann, 2006). This result is consistent with previous findings (e.g. Basson \& Rothmann, 2002; Schaufeli \& Bakker, 2004; Wissing, De Waal \& De Beer, 1992). The study by Naudé and Rothmann (2006) also shows that the availability of job resources (i.e. when distress regarding job resources is low) and personal resources (i.e. when the sense of coherence is strong) enhances work engagement levels.

The above discussion leads to the following hypotheses:

Hypothesis 1: Occupational stress and a weak sense of coherence predict burnout (i.e. exhaustion and depersonalisation) and low work engagement.
Hypothesis 2: Approach coping and seeking emotional/social support predict low burnout and high work engagement; whilst passive coping strategies (i.e. avoidance, turning to religion and focus on and ventilation of emotions) predict burnout and low work engagement.

\section{RESEARCH DESIGN}

\section{Research approach}

A cross-sectional survey was used to achieve the objectives of this research (Shaughnessy \& Zechmeister, 1997).

\section{Participants}

The study population consisted of registered nurses in private and public hospitals in South Africa. Random samples of nurses were taken from hospital wards, psychiatric wards, community/occupational services and nursing management. Descriptive information of the sample of registered nurses is provided in Table 1.

The sample consisted mainly of female, Afrikaans-speaking registered nurses, working in hospital wards in the private sector in Gauteng province. The mean age of the participants was 40 years, while the average duration of service in the nursing profession was 19 years. A total of $52.20 \%$ of the participants were Afrikaans speaking, $28.90 \%$ were English speaking, and $18.90 \%$ spoke an African language. The majority of the group took at least 21 days of leave during the year prior to the survey and $86.50 \%$ took sick leave comprising fewer than eight days

\section{Measurement battery}

The Nursing Stress Inventory (NSI) consists of 39 statements and was developed by Van der Colff and Rothmann (2006. Firstly, participants rated each of the 39 statements in terms of the perceived intensity of the particular stressor on a nine-point scale, ranging from 1 (low) to 9 (high). In the second part of the questionnaire, the participants were asked to respond in terms of perceived frequency of experiencing these stressors over the past six months on a 10-point scale ranging from 0 (no days) to $9+$ (more than 9 days). Exploratory factor analyses of the NSI in a sample of nurses resulted in three reliable factors, namely lack of organisational support (e.g. lack of supervisory or managerial support, and colleagues not doing their jobs), demands of the job (e.g. having to deal with constant unfamiliar situations, and making critical on-the-spot decisions) and nursing-specific demands (e.g. death of a patient, making a mistake during the treatment of a patient, and watching a patient suffer).

The Orientation to Life Questionnaire (OLQ) (Antonovsky, 1987) was used to measure the participants' sense of coherence. The OLQ consists of 29 items. Antonovsky (1993) reported Chronbach alpha coefficients of the OLQ in 29 research studies varying between 0.85 and 0.91 . Test-retest reliability studies found coefficients between 0.41 and 0.97 (Antonovsky, 1993). Rothmann (2002) reported an alpha coefficient of 0.89 for the OLQ, which may be regarded as acceptable (Nunnally \& Bernstein, 1994). In terms of the construct validity of the OLQ, it was found that a negative relationship exists between OLQ and experienced stress and that the OLQ correlates negatively with the 'State-Trait Anxiety Inventory-Trait' and the 'Beck Depression Inventory' (Frenz, Carey \& Jorgensen, 1993).

The Coping Orientation for Problem Experienced Questionnaire (COPE) (Carver, Scheier \& Weintraub, 1989) was used to measure the participants' general coping strategies. The COPE is a multidimensional 53-item questionnaire indicating the different ways in which individuals cope in different circumstances. Five factors were extracted for registered nurses, namely approach coping, seeking emotional or social support, avoidance as a strategy of coping, turning to religion, and focus on and ventilation of emotions. 
TABLE 1

Characteristics of registered nurses in the sample

\begin{tabular}{|c|c|c|c|}
\hline ITEM & CATEGORY & FREQUENCY & PERCENTAGE \\
\hline \multirow[t]{2}{*}{ Sector } & Private & 686 & 83.92 \\
\hline & Public & 132 & 16.08 \\
\hline \multirow[t]{3}{*}{ Rank } & Registered nurses & 554 & 67.70 \\
\hline & Unit managers/chief professional nurses & 122 & 14.90 \\
\hline & Middle and top managers & 142 & 17.40 \\
\hline \multirow[t]{4}{*}{ Unit } & Hospital ward & 613 & 79.40 \\
\hline & Psychiatric ward & 25 & 3.20 \\
\hline & Community/occupational services (Primary health care) & 67 & 8.70 \\
\hline & Management & 67 & 8.70 \\
\hline \multirow[t]{6}{*}{ Specialised unit } & Intensive and high care & 107 & 13.90 \\
\hline & Surgery, urology, ear, nose and throat, orthopaedic & 140 & 8.20 \\
\hline & Theatre and trauma/casualties & 184 & 24.00 \\
\hline & Medical, oncology, outpatients, paediatrics & 110 & 14.30 \\
\hline & Obstetrics & 59 & 7.70 \\
\hline & Psychiatry and other, e.g. community nursing/management & 168 & 21.90 \\
\hline \multirow[t]{6}{*}{ Years employed in nursing profession } & $0-10$ years & 162 & 19.80 \\
\hline & $10.01-15$ years & 159 & 19.40 \\
\hline & $15.01-20$ years & 180 & 22.00 \\
\hline & $20.01-25$ years & 130 & 15.90 \\
\hline & $25.01-30$ years & 107 & 13.10 \\
\hline & 30.01 and longer & 80 & 9.80 \\
\hline \multirow[t]{7}{*}{ Provinces } & Eastern Cape & 58 & 8.00 \\
\hline & Free State & 42 & 5.80 \\
\hline & Gauteng & 350 & 48.50 \\
\hline & KwaZulu-Natal & 135 & 18.70 \\
\hline & Mpumalanga & 46 & 6.40 \\
\hline & North West & 57 & 7.90 \\
\hline & Western Cape & 33 & 4.60 \\
\hline \multirow[t]{6}{*}{ Age } & $20-30$ & 164 & 20.00 \\
\hline & $30.1-35$ & 129 & 15.80 \\
\hline & $35.01-40$ & 117 & 14.30 \\
\hline & $40.01-45$ & 175 & 21.40 \\
\hline & $45.01-50$ & 112 & 13.70 \\
\hline & $50.01-60$ & 121 & 14.80 \\
\hline \multirow[t]{3}{*}{ Home language } & Afrikaans & 427 & 52.20 \\
\hline & English & 236 & 28.90 \\
\hline & African & 155 & 18.90 \\
\hline \multirow[t]{2}{*}{ Gender } & Male & 21 & 2.60 \\
\hline & Female & 791 & 97.40 \\
\hline
\end{tabular}

The COPE has been proven both reliable and valid in different cultural groups (Clark, Bornman, Cropanzano \& James, 1995; Van der Wateren, 1997). Carver et al. (1989) also reported alpha coefficients for the COPE ranging from 0.45 to 0.92 . With the exception of mental disengagement, which measures less than 0.60 , all the subscales demonstrate good levels of reliability. Test-retest reliability varies from 0.46 to 0.86 and 0.42 to 0.89 after two weeks (Carver et al., 1989). Acceptable reliability and validity levels have been determined for the COPE in South Africa, rendering it suitable for use in this context (Van der Wateren, 1997).

The Maslach Burnout Inventory-Human Services Survey (MBIHSS) (Maslach \& Jackson, 1986) was used to measure burnout in this study. The MBI-HSS consists of 22 items phrased as statements about personal feelings and attitudes that are selfscored on a seven-point frequency scale, ranging from 0 (never) to 6 (every day). The three subscales of the MBI-HSS include emotional exhaustion (nine items; e.g. 'I feel emotionally drained from my work'), depersonalisation (five items; e.g. 'I feel I treat some recipients as if they were impersonal objects'), and personal accomplishment (eight items; e.g. 'I have accomplished many worthwhile things in this job'). The psychometric soundness of the MBI-HSS is well documented in the literature, with internal consistencies usually well above the 0.70 Cronbach alpha level, except for the depersonalisation scale in some samples (Schaufeli, Bakker, Hoogduin, Schaap
\& Kladler, 2001). Test-retest reliability ranging from three months to one year has been reported in the range of 0.50 to 0.82 (Leiter \& Durup, 1996). The three-factor structure of the Maslach Burnout Inventory-Human Services Survey (MBIHSS) was confirmed. The factors showed acceptable construct equivalence for different language groups.

The Utrecht Work Engagement Scale (UWES) (Schaufeli et al., 2002) measures levels of engagement. The UWES is scored on a sevenpoint frequency scale, ranging from 0 (never) to 6 (every day). Three dimensions of engagement can be distinguished, namely vigour (six items; e.g. 'I am bursting with energy in my work'), dedication (five items; e.g. 'I find my work full of meaning and purpose') and absorption (six items; e.g. 'When I am working, I forget everything else around me'). In terms of internal consistency, reliability coefficients for the three subscales have been determined between 0.68 and 0.91 . Improvement of the alpha coefficient (ranging from 0.78 to 0.89 ) seems possible without adversely affecting the internal consistency of the scale (Storm \& Rothmann, 2003). The three-factor structure of work engagement (vigour, dedication and absorption) was not confirmed. Instead, a one-factor model of engagement reflected the best data fit. Van der Colff (2006) also found evidence for a one-factor model of work engagement. A biographical questionnaire was also administered. The participants were given the option of providing their names and contact details to 
TABLE 2

Descriptive statistics, alpha coefficients and Pearson correlations between the scales

\begin{tabular}{|c|c|c|c|c|c|c|c|c|c|c|c|c|c|c|c|}
\hline & MEAN & $S D$ & $\alpha$ & 1 & 2 & 3 & 4 & 5 & 6 & 7 & 8 & 9 & 10 & 11 & 12 \\
\hline 1. Emotional exhaustion & 22.15 & 11.28 & 0.88 & - & - & - & - & - & - & - & - & - & - & - & - \\
\hline 2. Depersonalisation & 4.86 & 4.46 & 0.73 & $0.59^{*}$ & - & - & - & - & - & - & - & - & - & - & - \\
\hline 3. Personal accomplishment & 22.60 & 5.20 & 0.71 & $-0.20^{*}$ & $-0.31^{*}$ & - & - & - & - & - & - & - & - & - & - \\
\hline 4. Engagement & 65.47 & 16.69 & 0.94 & $-0.41^{*}$ & $-0.33^{*}$ & $0.39^{*}$ & - & - & - & - & - & - & - & - & - \\
\hline 5. Lack of organisational support & 112.50 & 33.70 & 0.93 & $0.32^{*}$ & $0.22^{*}$ & -0.05 & $-0.13^{*}$ & - & - & - & - & - & - & - & - \\
\hline 6. Job demands & 83.05 & 25.58 & 0.91 & $0.35^{*}$ & $0.26^{*}$ & $-0.12^{*}$ & $-0.14^{*}$ & $0.64^{*}$ & - & - & - & - & - & - & - \\
\hline 7. Nursing-specific demands & 58.02 & 22.36 & 0.91 & $0.20^{*}$ & $0.14^{*}$ & -0.02 & $-0.10^{*}$ & $0.65^{*}$ & $0.54^{*}$ & - & - & - & - & - & - \\
\hline 8. Approach coping & 3.01 & 0.44 & 0.89 & $-0.07^{*}$ & $-0.12^{*}$ & $0.22^{*}$ & $0.35^{*}$ & 0.03 & 0.02 & -0.02 & - & - & - & - & - \\
\hline 9. Seeking emotional/social support & 2.91 & 0.62 & 0.86 & $-0.09^{*}$ & -0.07 & $0.19^{*}$ & $0.19^{*}$ & 0.06 & 0.03 & 0.07 & $0.45^{*}$ & - & - & - & - \\
\hline 10. Avoidance & 1.61 & 0.42 & 0.77 & $0.24^{*}$ & $0.27^{*}$ & $-0.23^{*}$ & $-0.11^{*}$ & $0.12^{*}$ & $0.18^{*}$ & 0.05 & $0.09^{*}$ & $0.08^{*}$ & - & - & - \\
\hline 11. Turning to religion & 3.25 & 0.84 & 0.90 & -0.04 & $-0.12^{*}$ & 0.04 & $0.16^{*}$ & 0.07 & 0.06 & 0.04 & $0.29^{*}$ & $0.23^{*}$ & $0.15^{*}$ & - & - \\
\hline 12. Focus on and ventilation of emotions & 2.44 & 0.77 & 0.67 & $0.32^{*}$ & $0.26^{*}$ & $-0.08^{*}$ & $-0.13^{*}$ & $0.23^{*}$ & $0.25^{*}$ & $0.18^{*}$ & $0.08^{*}$ & $0.28^{*}$ & $0.37^{*}$ & $0.09^{*}$ & - \\
\hline 13. Sense of coherence & 137.92 & 20.46 & 0.86 & $-0.49^{*}$ & $-0.47^{*}$ & $0.34^{*}$ & $0.42^{*}$ & $-0.23^{*}$ & $-0.28^{*}$ & $-0.15^{*}$ & $0.30^{*}$ & $0.18^{*}$ & $-0.35^{*}$ & $0.11^{*}$ & $-0.29^{*}$ \\
\hline
\end{tabular}

TABLE 3

${ }^{*} p<0.05$

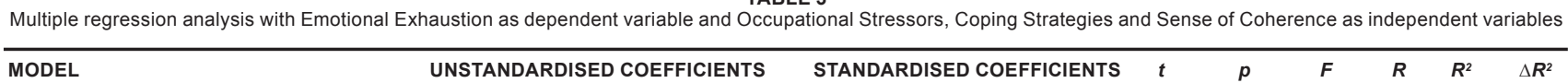

\begin{tabular}{|c|c|c|c|c|c|c|c|c|c|c|}
\hline \multirow{2}{*}{\multicolumn{2}{|c|}{ MODEL }} & \multicolumn{2}{|c|}{ UNSTANDARDISED COEFFICIENTS } & \multirow{2}{*}{$\begin{array}{l}\text { STANDARDISED COEFFICIENTS } \\
\text { Beta }\end{array}$} & \multirow[t]{2}{*}{$t$} & \multirow[t]{2}{*}{$p$} & \multirow[t]{2}{*}{$F$} & \multirow[t]{2}{*}{$R$} & \multirow[t]{2}{*}{$R^{2}$} & \multirow[t]{2}{*}{$\Delta R^{2}$} \\
\hline & & B & SE & & & & & & & \\
\hline \multirow[t]{4}{*}{1} & (Constant) & 7.110 & 1.40 & - & 5.10 & 0.00 & $44.21^{*}$ & 0.37 & 0.14 & $0.14^{*}$ \\
\hline & Stress: lack of organisational support & 0.060 & 0.02 & 0.19 & 3.89 & $0.00^{*}$ & & & & \\
\hline & Stress: job demands & 0.120 & 0.02 & 0.27 & 6.14 & $0.00^{*}$ & & & & \\
\hline & Stress: nursing-specific demands & -0.030 & 0.02 & -0.06 & -1.45 & 0.15 & & & & \\
\hline \multirow[t]{5}{*}{2} & (Constant) & 43.479 & 2.96 & - & 14.70 & 0.00 & $86.79^{*}$ & 0.55 & 0.30 & $0.16^{*}$ \\
\hline & Stress: lack of organisational support & 0.050 & 0.02 & 0.14 & 3.21 & $0.00^{*}$ & & & & \\
\hline & Stress: job demands & 0.080 & 0.02 & 0.17 & 4.32 & $0.00^{*}$ & & & & \\
\hline & Stress: nursing-specific demands & -0.020 & 0.02 & -0.04 & -1.13 & 0.27 & & & & \\
\hline & Sense of coherence & -0.230 & 0.02 & -0.42 & -13.59 & $0.00^{*}$ & & & & \\
\hline \multirow[t]{10}{*}{3} & (Constant) & 35.440 & 3.76 & - & 9.41 & 0.00 & $43.90^{*}$ & 0.57 & 0.33 & $0.03^{*}$ \\
\hline & Stress: lack of organisational support & 0.040 & 0.01 & 0.13 & 2.92 & $0.00^{*}$ & & & & \\
\hline & Stress: job demands & 0.070 & 0.02 & 0.15 & 3.77 & $0.00^{*}$ & & & & \\
\hline & Stress: nursing-specific demands & -0.020 & 0.02 & -0.04 & -0.93 & 0.35 & & & & \\
\hline & Sense of coherence & -0.200 & 0.02 & -0.37 & -10.45 & $0.00^{*}$ & & & & \\
\hline & Approach coping & 0.070 & 0.04 & 0.07 & 1.97 & $0.05^{\star}$ & & & & \\
\hline & Seeking emotional/ social support & -0.210 & 0.07 & -0.11 & -3.13 & $0.00^{*}$ & & & & \\
\hline & Avoidance & 0.040 & 0.07 & 0.02 & 0.62 & 0.54 & & & & \\
\hline & Turning to religion & -0.100 & 0.10 & -0.03 & -0.99 & 0.32 & & & & \\
\hline & Focus on and ventilation of emotions & 0.840 & 0.17 & 0.17 & 5.08 & $0.00^{*}$ & & & & \\
\hline
\end{tabular}

${ }^{*} p<0.05$

be given feedback. Other information gathered included rank, unit, education, gender and language.

\section{Statistical analysis}

The statistical analysis was conducted by means of the SPSS Program Version 12 (SPSS Inc., 2003). Cronbach alpha coefficients $(\alpha)$ were used to assess the reliability of the measuring instruments (Clark \& Watson, 1995). Descriptive statistics (e.g. means and standard deviations) were used to analyse the data. Pearson product-moment correlation coefficients were used to specify the relationships between the variables. The level of statistical significance was set at $p<0.05$. Standard multiple regression analysis was carried out to assess the contribution of the independent variables (occupational stress and job satisfaction) to burnout and work engagement.

\section{RESULTS}

The descriptive statistics, alpha coefficients and Pearson correlations for the extracted factors of the measuring instruments for registered nurses are reported in Table 2.

According to Table 2, the scores of the MBI-HSS, UWES, NSI, COPE and OLQ are distributed normally. The Cronbach alpha coefficients of all the measuring instruments are considered to be acceptable compared to the guideline of $\alpha>0.70$ (Nunnally \& Bernstein, 1994), except for focus on and ventilation of emotions as a coping strategy, where the Cronbach alpha coefficient is slightly lower than 0.70 (i.e. 0.67). This correlates with the results reported by Carver et al. (1989), who reported alpha coefficients for the COPE ranging from 0.45 to 0.92 . It therefore appears that MBI-HSS, UWES, NSI, COPE and OLQ have acceptable levels of reliability.

Moreover, Table 2 shows that emotional exhaustion is strongly related to depersonalisation and moderately related to organisational support, job demands, and focus on and ventilation of emotions. Emotional exhaustion is also moderately negatively related to work engagement and sense of coherence. Depersonalisation is moderately and negatively related to personal accomplishment, work engagement and sense of coherence. Personal accomplishment is moderately related to work engagement and sense of coherence, whereas work engagement is moderately related to approach coping and sense of coherence.

Multiple regression analysis was conducted to assess whether or not occupational stress, sense of coherence and coping strategies predict burnout and the work engagement 
TABLE 4

Multiple regression analysis with Depersonalisation as dependent variable and Occupational Stressors, Coping Strategies and Sense of Coherence as independent variables

\begin{tabular}{|c|c|c|c|c|c|c|c|c|c|c|}
\hline \multicolumn{2}{|c|}{ MODEL } & \multicolumn{2}{|c|}{ UNSTANDARDISED COEFFICIENTS } & \multirow{2}{*}{$\frac{\text { STANDARDISED COEFFICIENTS }}{\text { Beta }}$} & \multirow[t]{2}{*}{$t$} & \multirow[t]{2}{*}{$p$} & \multirow[t]{2}{*}{$F$} & \multirow[t]{2}{*}{$R$} & \multirow[t]{2}{*}{$R^{2}$} & \multirow[t]{2}{*}{$\Delta R^{2}$} \\
\hline & & B & SE & & & & & & & \\
\hline \multirow[t]{4}{*}{1} & (Constant) & 1.64 & 0.76 & - & 2.16 & 0.03 & $20.74^{*}$ & 0.27 & 0.07 & $0.07^{*}$ \\
\hline & Stress: lack of organisational support & 0.02 & 0.01 & 0.11 & 2.28 & $0.02^{*}$ & & & & \\
\hline & Stress: job demands & 0.05 & 0.01 & 0.21 & 4.56 & $0.00^{*}$ & & & & \\
\hline & Stress: nursing-specific demands & -0.01 & 0.01 & -0.04 & -0.95 & 0.34 & & & & \\
\hline \multirow[t]{5}{*}{2} & (Constant) & 21.29 & 1.62 & - & 13.16 & 0.00 & $64.00^{*}$ & 0.49 & 0.24 & $0.17^{*}$ \\
\hline & Stress: lack of organisational support & 0.01 & 0.01 & 0.07 & 1.44 & 0.15 & & & & \\
\hline & Stress: job demands & 0.03 & 0.01 & 0.11 & 2.61 & $0.01^{*}$ & & & & \\
\hline & Stress: nursing-specific demands & -0.01 & 0.01 & -0.02 & -0.57 & 0.57 & & & & \\
\hline & Sense of coherence & -0.12 & 0.01 & -0.43 & -13.42 & $0.00^{*}$ & & & & \\
\hline \multirow[t]{10}{*}{3} & (Constant) & 17.08 & 2.07 & - & 8.27 & 0.00 & $32.77^{\star}$ & 0.52 & 0.27 & $0.07^{*}$ \\
\hline & Stress: lack of organisational support & 0.01 & 0.01 & 0.06 & 1.42 & 0.16 & & & & \\
\hline & Stress: job demands & 0.02 & 0.01 & 0.09 & 2.21 & $0.03^{*}$ & & & & \\
\hline & Stress: nursing-specific demands & -0.01 & 0.01 & -0.02 & -0.45 & 0.65 & & & & \\
\hline & Sense of coherence & -0.10 & 0.01 & -0.35 & -9.66 & $0.00^{*}$ & & & & \\
\hline & Approach coping & 0.01 & 0.02 & 0.01 & 0.22 & 0.83 & & & & \\
\hline & Seeking emotional/ social support & -0.03 & 0.04 & -0.03 & -0.69 & 0.49 & & & & \\
\hline & Avoidance & 0.12 & 0.04 & 0.11 & 3.19 & $0.00^{*}$ & & & & \\
\hline & Turning to religion & -0.19 & 0.06 & -0.11 & -3.32 & $0.00^{*}$ & & & & \\
\hline & Focus on and ventilation of emotions & 0.84 & 0.17 & 0.17 & 5.08 & $0.00^{*}$ & & & & \\
\hline
\end{tabular}
${ }^{*} p<0.05$

Multiple regression analysis with Personal Accomplishment as dependent variable and Occupational Stressors, Coping Strategies and Sense of Coherence as independent

\begin{tabular}{|c|c|c|c|c|c|c|c|c|c|c|}
\hline \multirow{2}{*}{\multicolumn{2}{|c|}{ MODEL }} & \multicolumn{2}{|c|}{ UNSTANDARDISED COEFFICIENTS } & \multirow{2}{*}{$\begin{array}{l}\text { STANDARDISED COEFFICIENTS } \\
\text { Beta }\end{array}$} & \multirow[t]{2}{*}{$t$} & \multirow[t]{2}{*}{$p$} & \multirow[t]{2}{*}{$F$} & \multirow[t]{2}{*}{$R$} & \multirow[t]{2}{*}{$R^{2}$} & \multirow[t]{2}{*}{$\Delta R^{2}$} \\
\hline & & B & SE & & & & & & & \\
\hline \multirow[t]{4}{*}{1} & (Constant) & 36.88 & 1.00 & - & 36.81 & 0.00 & 4.63 & 0.13 & 0.02 & 0.02 \\
\hline & Stress: lack of organisational support & 0.01 & 0.01 & 0.02 & 0.42 & 0.68 & & & & \\
\hline & Stress: job demands & -0.05 & 0.01 & -0.16 & -3.46 & $0.00^{*}$ & & & & \\
\hline & Stress: nursing-specific demands & 0.02 & 0.02 & 0.06 & 1.20 & 0.23 & & & & \\
\hline \multirow[t]{5}{*}{2} & (Constant) & 17.29 & 2.23 & - & 7.76 & 0.00 & $27.47^{*}$ & 0.35 & 0.12 & $0.10^{*}$ \\
\hline & Stress: lack of organisational support & 0.01 & 0.01 & 0.06 & 1.22 & 0.22 & & & & \\
\hline & Stress: job demands & -0.03 & 0.01 & -0.09 & -1.90 & 0.06 & & & & \\
\hline & Stress: nursing-specific demands & 0.01 & 0.02 & 0.04 & 0.92 & 0.36 & & & & \\
\hline & Sense of coherence & 0.12 & 0.01 & 0.33 & 9.72 & $0.00^{*}$ & & & & \\
\hline \multirow[t]{10}{*}{3} & (Constant) & 18.30 & 2.81 & - & 6.50 & 0.00 & $18.13^{*}$ & 0.41 & 0.17 & $0.05^{*}$ \\
\hline & Stress: lack of organisational support & 0.01 & 0.01 & 0.04 & 0.87 & 0.39 & & & & \\
\hline & Stress: job demands & -0.02 & 0.01 & -0.08 & -1.77 & 0.08 & & & & \\
\hline & Stress: nursing-specific demands & 0.01 & 0.02 & 0.03 & 0.77 & 0.44 & & & & \\
\hline & Sense of coherence & 0.08 & 0.01 & 0.22 & 5.67 & $0.00^{*}$ & & & & \\
\hline & Approach coping & 0.10 & 0.03 & 0.13 & 3.46 & $0.00^{*}$ & & & & \\
\hline & Seeking emotional/ social support & 0.14 & 0.05 & 0.11 & 2.74 & $0.01^{*}$ & & & & \\
\hline & Avoidance & -0.24 & 0.05 & -0.17 & -4.58 & $0.00^{*}$ & & & & \\
\hline & Turning to religion & -0.06 & 0.08 & -0.03 & -0.78 & 0.43 & & & & \\
\hline & Focus on and ventilation of emotions & 0.04 & 0.12 & 0.01 & 0.29 & 0.77 & & & & \\
\hline
\end{tabular}

${ }^{*} p<0.05$

of registered nurses. Table 3 shows the results of multiple regression analysis, with exhaustion (as measured by the MBIHSS) as the dependent variable, and occupational stressors (as measured by the NSI), coping strategies (as measured by the COPE) and sense of coherence (as measured by the OLQ) as the independent variables.

The results in Table 3 indicate that two occupational stress dimensions, namely lack of organisational support and job demands, predicted $14 \%$ of the variance in emotional exhaustion $\left(F=44.21, p<0.01, \Delta R^{2}=0.14\right)$. Adding sense of coherence as an independent variable (in step 2) resulted in a statistically significant increase in the prediction of the variance in emotional exhaustion $\left(\Delta F=184.61, p<0.01, \Delta R^{2}=0.16\right)$. Furthermore, entering coping strategies into the regression analysis (step 3) resulted in a statistically significant increase in the variance of emotional exhaustion predicted $(\Delta F=7.02$, $\left.p<0.01, \Delta R^{2}=0.03\right)$. The regression coefficients of two stressors, namely stress: lack of organisational support $(\beta=0.13, p<0.01)$, and stress: job demands ( $\beta=0.17, p<0.01)$, sense of coherence $(\beta=-0.37, p<0.01)$, as well as three coping strategies, namely approach coping $(\beta=0.07, p<0.05)$, seeking emotional/social support $(\beta=-0.11, p<0.01)$ and focus on and ventilation of emotions $(\beta=0.17, p<0.01)$ were statistically significant. In sum, occupational stress, a weak sense of coherence, approach coping, focus on and ventilation of emotions, and low seeking of emotional/social support predicted $33 \%$ of the variance in emotional exhaustion.

Table 4 shows the results of the multiple regression analysis with depersonalisation (as measured by the MBI-HSS) as the dependent variable, and occupational stressors (as measured by the NSI), coping strategies (as measured by the COPE) and sense of coherence (as measured by the OLQ) as the independent 
TABLE 6

Multiple regression analysis with Work Engagement as dependent variable and Occupational Stressors, Coping Strategies and Sense of Coherence as independent variables

\begin{tabular}{|c|c|c|c|c|c|c|c|c|c|c|}
\hline \multicolumn{2}{|c|}{ MODEL } & \multicolumn{2}{|c|}{ UNSTANDARDISED COEFFICIENTS } & \multirow{2}{*}{$\frac{\text { STANDARDISED COEFFICIENTS }}{\text { Beta }}$} & \multirow[t]{2}{*}{$t$} & \multirow[t]{2}{*}{$p$} & \multirow[t]{2}{*}{$F$} & \multirow[t]{2}{*}{$R$} & \multirow[t]{2}{*}{$R^{2}$} & \multirow[t]{2}{*}{$\Delta R^{2}$} \\
\hline & & B & SE & & & & & & & \\
\hline \multirow[t]{4}{*}{1} & (Constant) & 74.52 & 2.20 & - & 33.87 & 0.00 & 6.16 & 0.15 & 0.02 & 0.02 \\
\hline & Stress: lack of organisational support & -0.03 & 0.03 & -0.06 & -1.11 & 0.27 & & & & \\
\hline & Stress: job demands & -0.07 & 0.03 & -0.10 & -2.13 & $0.03^{*}$ & & & & \\
\hline & Stress: nursing-specific demands & -0.01 & 0.04 & -0.01 & -0.24 & 0.81 & & & & \\
\hline \multirow[t]{5}{*}{2} & (Constant) & 21.48 & 4.74 & - & 4.53 & 0.00 & $43.71^{*}$ & 0.42 & 0.18 & $0.16^{*}$ \\
\hline & Stress: lack of organisational support & -0.01 & 0.02 & -0.01 & -0.21 & 0.83 & & & & \\
\hline & Stress: job demands & -0.00 & 0.03 & -0.01 & -0.12 & 0.90 & & & & \\
\hline & Stress: nursing-specific demands & -0.02 & 0.03 & -0.03 & -0.71 & 0.48 & & & & \\
\hline & Sense of coherence & 0.34 & 0.03 & 0.41 & 12.37 & $0.00^{*}$ & & & & \\
\hline \multirow[t]{10}{*}{3} & (Constant) & 5.83 & 5.93 & - & 0.98 & 0.33 & $28.32^{*}$ & 0.49 & 0.24 & $0.06^{*}$ \\
\hline & Stress: lack of organisational support & -0.02 & 0.02 & -0.04 & -0.78 & 0.44 & & & & \\
\hline & Stress: job demands & -0.01 & 0.03 & -0.02 & -0.52 & 0.61 & & & & \\
\hline & Stress: nursing-specific demands & -0.01 & 0.32 & -0.01 & -0.24 & 0.81 & & & & \\
\hline & Sense of coherence & 0.25 & 0.03 & 0.30 & 8.18 & $0.00^{*}$ & & & & \\
\hline & Approach coping & 0.39 & 0.06 & 0.25 & 6.73 & $0.00^{*}$ & & & & \\
\hline & Seeking emotional/social support & 0.13 & 0.11 & 0.04 & 1.16 & 0.25 & & & & \\
\hline & Avoidance & -0.02 & 0.11 & -0.01 & -0.15 & 0.88 & & & & \\
\hline & Turning to religion & 0.04 & 0.16 & 0.01 & 0.22 & 0.83 & & & & \\
\hline & Focus on and ventilation of emotions & -0.39 & 0.26 & -0.53 & -1.48 & 0.14 & & & & \\
\hline
\end{tabular}

variables. The results in Table 4 indicate that two occupational stress dimensions, namely lack of organisational support and job demands, predicted $7 \%$ of the variance in depersonalisation $\left(F=678.51, p<0.01, \Delta R^{2}=0.07\right)$. Adding sense of coherence as an independent variable (in step 2) resulted in a statistically significant increase in the prediction of the variance in depersonalisation $\left(\Delta F=180.10, p<0.01, \Delta R^{2}=0.17\right)$. Furthermore, entering coping strategies into the regression analysis (step 3) resulted in a further statistically significant increase in the variance of depersonalisation predicted $(\Delta F=6.16, p<0.01$, $\left.\Delta R^{2}=0.03\right)$. The regression coefficients of stress: job demands $(\beta=0.09, p<0.03)$, sense of coherence $(\beta-0.35, p<0.01)$ and three coping strategies, namely avoidance $(\beta=0.11, p<0.01)$, turning to religion $(\beta=-0.11, p<0.01)$ and focus on and ventilation of emotions $(\beta=0.17, p<0.01)$, were statistically significant. In total, occupational stress, a weak sense of coherence, avoidance coping, focus on and ventilation of emotions, and a low turning to religion predicted $27 \%$ of the variance in depersonalisation.

The results of a multiple regression analysis with occupational stressors (asmeasured by theNSI), coping strategies (asmeasured by the COPE), and sense of coherence (as measured by the OLQ) as independent variables, and personal accomplishment (as measured by the MBI-HSS) as the dependent variable, are reported in Table 5.

The results in Table 5 reveal that one occupational stress dimension, namely job demands, predicted $2 \%$ of the variance in personal accomplishment $\left(F=2.62, p<0.01, \Delta R^{2}=0.02\right)$. Adding sense of coherence as an independent variable (in step 2) resulted in a statistically significant increase in the prediction of the variance in personal accomplishment $\left(\Delta F=94.42, p<0.01, \Delta R^{2}=0.10\right)$. Furthermore, entering coping strategies into the regression analysis (step 3 ) resulted in a statistically significant increase in the variance of personal accomplishment predicted $\left(\Delta F=9.51, p<0.01, \Delta R^{2}=0.05\right)$. The regression coefficients of sense of coherence $(\beta=0.22, p<0.01)$, and three coping strategies, namely approach coping $(\beta=0.13$, $p<0.01)$, seeking emotional/social support $(\beta=0.11, p<0.01)$ and avoidance $(\beta=-0.17, p<0.01)$, were statistically significant. In total, occupational stress because of job demands, a strong sense of coherence, approach-coping strategies, focus on and ventilation of emotion, and not making use of avoidance as a coping strategy predicted $17 \%$ of the variance in personal accomplishment.
Table 6 shows the results of a multiple regression analysis with work engagement (as measured by the UWES) as the dependent variable and occupational stressors (as measured by the NSI), coping strategies (as measured by the COPE) and sense of coherence (as measured by the OLQ) as the independent variables.

The results in Table 6 indicate that one occupational stress dimension, namely job demands, predicted $2 \%$ of the variance in engagement $\left(F=1683.06, p<0.01, \Delta R^{2}=0.02\right)$. Adding sense of coherence as an independent variable (in step 2) resulted in a statistically significant increase in the prediction of the variance in engagement $\left(\Delta F=152.90, p<0.01, \Delta R^{2}=0.16\right)$. Furthermore, entering coping strategies into the regression analysis (step 3) resulted in a statistically significant increase in the variance of engagement predicted $\left(\Delta F=13,36, p<0.01, \Delta R^{2}=0.06\right)$. The regression coefficients of sense of coherence $(\beta=0.30, p<0.01)$ and one coping strategy, namely approach coping $(\beta=0.25$, $p<0.01$ ), were statistically significant. In total, low levels of occupational stress because of job demands, a strong sense of coherence, and approach-coping strategies predicted $24 \%$ of the variance in engagement.

\section{DISCUSSION}

The aim of this study was to investigate the relationship between occupational stress, sense of coherence, coping, burnout and work engagement in registered nurses in South Africa, using a cross-sectional survey design.

The sample consisted of 818 registered nurses. Registered nurses experience the following stressors relating to lack of organisational support as relatively severe: staff shortage, inadequate salary, insufficient personnel to handle the workload, fellow workers not doing their jobs and poorly motivated coworkers. The following stressors relating to job demands were experienced as relatively severe: excessive administrative duties, demands from clients/patients and health risks posed by contact with patients. Regarding stress due to nursingspecific demands, performing painful procedures on patients and watching a patient suffer were identified as the two most intense stressors, although these items measured low on the frequency scale, hence the lower scores on the severity scale. Of all the stressors, staff shortage was rated as the most severe, with inadequate salaries and excessive administrative duties 
next in line. Most of the above stressors have already been noted in the literature (see Happel et al., 2003; McGrath et al., 2003), except for health risks posed by contact with patients. This could be explained by the high incidence of HIV and AIDS in South Africa. Occupational stress due to a lack of organisational support and job demands contributed significantly to emotional exhaustion and depersonalisation. This confirms the results of Demerouti et al. (2000), who explain that the relationship between a lack of resources (organisational support) and depersonalisation is to be found in theories about work motivation, e.g. Herzberg's two-factor hygiene theory and Maslow's hierarchy of needs theory. A lack of fulfilment of basic hygiene factors or basic needs (enough resources) will cause employees to withdraw and develop indifferent attitudes towards their jobs. In light of the results of this study regarding the lack of organisational support (lack of resources), this should be a concern for organisations, as disengagement from or depersonalised feelings towards patients (treating patients as nothing more than mere objects) should be prevented at all costs.

While occupational stressors seem to contribute to the distress of registered nurses (as indicated by emotional exhaustion and depersonalisation) in terms of engagement and personal accomplishment, the results suggest that no significant relationships exist between occupational stress on the one hand, and engagement and personal accomplishment on the other. In this regard, Schaufeli and Bakker (2004) stated that personal accomplishment and work engagement form part of an extended engagement factor, while emotional exhaustion and depersonalisation form part of a burnout factor.

Moreover, the results of this study show that burnout (emotional exhaustion) was moderately related to work engagement, while depersonalisation was related to both personal accomplishment and work engagement. Therefore, occupational stress could possibly impact on work engagement through its effect on burnout (emotional exhaustion and depersonalisation) However, empirical studies have revealed that engagement at work can prevail despite high job demands and long working hours (Schaufeli \& Bakker, 2001). If one considers that statements regarding occupational stress were formulated in a negative way in the present study, the expected relationship with engagement would never be achieved due to the positive formulation of items measuring engagement. Furthermore, the measurement of job demands and lack of job resources was not done independently of experienced strain in the present study, which could have influenced the findings.

A statistical analysis of the effects of sense of coherence on burnout and work engagement revealed that a strong sense of coherence predicted lower levels of emotional exhaustion and depersonalisation, and vice versa. Thus, registered nurses seem to experience a depletion of emotional resources when they demonstrate a weak sense of coherence. This result was also found to be true for personal accomplishment and work engagement, where a strong sense of coherence predicted higher levels of personal accomplishment and work engagement, and vice versa. This could possibly be explained by a predisposition to experience stimuli from the environment in a positive interpretative manner. They could also perceive stimuli as making sense on a cognitive level, perceive to be in control of events by means of support networks, and view events as motivationally relevant and meaningful. This result is consistent with previous findings (e.g. Basson \& Rothmann, 2002; Naudé \& Rothmann, 2006; Schaufeli \& Bakker, 2004; Wissing et al., 1992). According to Hobfoll (2001), burnout and low work engagement are the result of failure to acquire sufficient resources. Burnout and low work engagement might thus occur due to a lack of resources. Demerouti et al. (2000) stated in this regard that job demands are related to feelings of exhaustion, but also agree with Hobfoll that a lack of job resources is related to disengagement from or feelings of depersonalisation towards patients.

It was also evident from the results that registered nurses with a strong sense of coherence coped better with occupational stress due to a lack of organisational support and job demands. Registered nurses with a weak sense of coherence would probably find it difficult to structure their world to be understandable, orderly and consistent. They might tend to experience the events of life as unmanageable, perceive that they lack the resources to meet the demands and thus feel that life does not make sense on an emotional level (Antonovsky, 1987). They would therefore understandably perceive situations as stressful. The results further revealed that a strong sense of coherence allows nurses to make use of active coping strategies (i.e. seeking emotional/social support) and thus to deal with occupational stressors in a positive, problem-solving manner.

Sense of coherence was the only variable in this study related to personal accomplishment. Several scholars have argued that personal accomplishment reflects a personality characteristic rather than a genuine burnout component (Cordes \& Dougherty, 1993; Shirom, 1989). Antonovsky (1987) also regards sense of coherence as a personality disposition.

The results regarding coping strategies showed that a relationship exists between emotional exhaustion and focus on and venting of emotions, meaning that nurses who make use of this coping strategy revealed higher levels of emotional exhaustion. The other side of the coin might also be true, namely that focus on and ventilation of emotions could be a result of depleted energy levels due to burnout (emotional exhaustion), causing nurses to feel frustrated because they cannot perform their duties effectively. However, Payne (2001) warns that focus on and ventilation of emotions as a coping strategy will always be part of coping for nurses, since many stressors in nursing cannot be changed. On the other hand, approach coping was found to be related to work engagement and sense of coherence, where nurses with a strong sense of coherence make use of approach coping as a coping strategy and therefore are taking charge of their situation and problems or stressors in the workplace, which also enhances work engagement.

In summary, occupational stress, a weak sense of coherence, approach coping, focus on and ventilation of emotions, and low seeking of emotional/social support predicted $33 \%$ of the variance in emotional exhaustion. Twenty-seven percent of the variance in depersonalisation was predicted by occupational stress, a weak sense of coherence, avoidance coping, focus on and ventilation of emotions, and a low turning to religion. Occupational stress because of job demands, a weak sense of coherence, approach-coping strategies, focus on and ventilation of emotion, and not making use of avoidance as a coping strategy predicted $17 \%$ of the variance in personal accomplishment, while low levels of occupational stress because of job demands, a weak sense of coherence, and approach-coping strategies predicted $24 \%$ of the variance in engagement. The above results confirm both hypotheses, namely that 1) Occupational stress and a weak sense of coherence predict burnout and low work engagement; and 2) Approach coping and seeking emotional/ social support predict low burnout and high work engagement; whilst passive coping strategies (i.e. avoidance, turning to religion and focus on and ventilation of emotions) predict burnout and low work engagement.

The limitations of the present study include the use of a crosssectional survey design, which makes it difficult to prove causal relationships. A longitudinal design would have been the preferred method to analyse causal relationships. Another limitation is the exclusive use of self-report measures, a strategy often associated with method variance. Sample size further limits the research results in such a way that results cannot be generally applied to all registered nurses in South Africa. 


\section{Recommendations}

Organisations can contribute to the development of employees' sense of coherence by providing information in a consistent, structured, ordered and understandable format. In order for employees to perceive that work expectations are manageable and within their, or important other peoples power, employers should ensure that employees are equipped with the necessary knowledge, skills, material, instruments and other resources, and that there is a balance in the load of tasks to be handled. Employees should also be given the opportunity to perform work that requires thought and independent judgement. Employees will regard their work as meaningful when a degree of independence and freedom of choice is allowed in the performance of their tasks. Participation in decision making will enhance the employees' feeling of membership and contribute to the meaningfulness component of sense of coherence. Moreover, the employee should have the freedom to disagree with his/her supervisor, to be able to discuss what to do with his/her supervisor and to act autonomously.

Job demands and a lack of organisational support should be managed by the organisation to prevent burnout of nurses and to contribute to their work engagement. Coping strategies are also important areas of intervention. It is necessary to analyse the results of this study in each hospital or institution before any intervention is planned. While some occupational stressors were found consistently in all the hospitals included in this study, the stressors in the different hospitals were quite different. Tailor-made interventions for a specific hospital are necessary to ensure that the planned effects are yielded (Kompier \& Cooper, 1999).

Better relationships amongst members of the professional team (e.g. doctors and other nurses, including supervisors) may also relieve stress. McGrath et al. (2003) suggest that this could be achieved by means of closer integration during training to enhance an understanding of each other's role, as well as implementing a higher level of education for nurses, which might lead to increased confidence and an ability to discuss issues as equals with professional colleagues. The problem of staff shortages needs to be addressed. A re-evaluation of salaries might be a good point of departure in addressing this problem. Inadequate salaries might cause registered nurses to leave the profession, and often even the country, for the sake of opportunities that offer better financial rewards. More research is needed regarding the organisational factors that affect burnout and work engagement.

\section{AUTHOR'S NOTE}

The material described in this article is based on work supported by the National Research Foundation under grant number 2053917.

\section{REFERENCES}

Alsoofi, M.A., Al-Heeti, K.N., \& Alwashli, A. (2000, July). Burnout and its relationship with job stress and coping with stress for Yemeni teachers. Paper presented at the 28th International Congress of Psychology, Stockholm, Sweden.

Amirkhan, J.H., \& Greaves, H. (2003). Sense of coherence and stress: The mechanics of a healthy disposition. Psychology and Health, 18(1), 31-62.

Antonovsky, A. (1987). Unravelling the mystery of health: How people manage stress and stay well. San Francisco: Jossey-Bass.

Antonovsky, A. (1993). The structure and properties of the sense of coherence scale. Social Science and Medicine, 36, 725-733.

Basson, M.J., \& Rothmann, S. (2002). Sense of coherence, coping and burnout of pharmacists. South African Journal of Economic and Management Sciences, 5(1), 35-62.

Basson, C.J., \& Van der Merwe, T. (1994). Occupational stress and coping in a sample of student nurses. Curationis, 17(4), 35-43.

Bhagat, R.S., Ford, D.L., O’Driscoll, M.P., Frey, L., Babakus, E., \& Mahanyele, M. (2001). Do South African managers cope differently from American managers? A cross-cultural investigation. International Journal of Intercultural Relations, 25, 301-313.

Carson, J., Bartlett, H., \& Croucher, P. (1991). Stress in community psychiatric nursing: A preliminary investigation. Community Psychiatric Nursing Journal, 11, 8-12.

Carver, C.S., Scheier, M.R., \& Weintraub, J.K. (1989). Assessing coping strategies: A theoretically based approach. Journal of Personality and Social Psychology, 56, 267-283.

Cavanagh, S.J. (1997). Educational sources of stress in midwifery students. Nurse Education Today, 17, 128-134.

Cherniss, C. (1995). Beyond burnout. New York: Routledge.

Clark, K.K., Bornman, C.A., Cropanzano, R.S., \& James, K. (1995). Validation evidence for three coping measures. Journal of Personality Assessment, 65, 434-455.

Clark, L.A., \& Watson, D. (1995). Constructing validity: Basic issues in objective scale development. Psychological Assessment, 7, 309-319.

Cocco, E., Gatti, M., De Mendonça Lima, C.A., \& Camus, V. (2003). A comparative study of stress and burnout among staff caregivers in nursing homes and acute geriatric wards. International Journal of Geriatric Psychiatry, 18, 78-85.

Coffey, M., \& Coleman, M. (2001). The relationship between support and stress in forensic community mental health nursing. Journal of Advanced Nursing, 34, 397-407.

Cordes, C.L., \& Dougherty, T.W. (1993). A review and an integration of research on job burnout. Academy of Management Review, 18, 621-656.

Csikszentmihalyi, M. (1997). Intrinsic motivation and effective teaching: A flow analysis. In J.L. Bess (Ed.), Teaching well and liking it: Motivating faculty to teach effectively. London: John Hopkins University Press.

Demerouti, E., Bakker, A.B., Nachreiner, F., \& Schaufeli, W.B. (2000.). A model of burnout and life satisfaction amongst nurses. Journal of Advanced Nursing, 32, 454-464.

Erasmus, L., Poggenpoel, M., \& Gmeiner, A. (1998). Beroepsmatheidervaring by psigiatriese verpleegkundiges in 'n privaat psigiatriese hospital. Curationis, 21(1), 9-16.

Fagin, L., Brown, D., Bartlett, H., Leary, J., \& Carson, J. (1995). The Claybury community psychiatric nurse stress study: Is it more stressful to work in hospital or the community? Journal of Advanced Nursing, 22, 347-358.

Feldt, T. (1997). The role of sense of coherence in well-being at work: Analysis of main and moderator effects. Work and Stress, 11, 134-147.

Fleishman, J.A. (1984). Personality characteristics and coping patterns. Journal of Health and Social Behavior, 25, 229-234.

Folkman, S., \& Lazarus, R.S. (1984). Stress, appraisal and coping. New York: Springer.

Fox, M., Dwyer, D., \& Ganster, D. (1993). Effects of stressful job demands and control of physiological and attitudinal outcomes in a hospital setting. Academy of Management Journal, 36, 289-318.

French, J.R.P., Jr., Kaplan, R.D., \& Harrison, R.V. (1982). The mechanisms of job stress and strain. Chichester: Wiley.

Frenz, A.W., Carey, M.P., \& Jorgensen, R.S. (1993). Psychometric evaluation of Antonovsky's sense of coherence scale. Psychological Assessment, 5, 145-153.

Glass, D.C., McKnight, J.D., \& Valdimarsdottir, H. (1993). Depression, burnout, and perceptions of control in hospital nurses. Journal of Consulting and Clinical Psychology, 61, 147155.

Happel, B., Pinikahana, J., \& Martin, T. (2003). Stress and burnout in forensic psychiatric nursing. Stress and Health, 19, 63-68.

Hobfoll, S.E. (2001). The influence of culture, community and the nested-self in the stress process: Advancing conservation of resources theory. Applied Psychology: An International Review, 50, 337-369.

Holroyd, K.A., \& Lazarus, R.S. (1982). Stress, coping and somatic adaptation. In L. Goldberger \& S. Breznitz (Eds.), Handbook of stress: Theoretical and clinical aspects (pp. 21-35). New York: Free Press.

Kilfedder, C.J., Power, K.G., \& Wells, T.J. (2001). Burnout in psychiatric nursing. Journal of Advanced Nursing, 34, 383396. 
Kleinke, C.L. (1991). Coping with life challenges. San Francisco: Brooks/Cole.

Kompier, M., \& Cooper, C. (1999). Preventing stress, improving productivity. London: Routledge.

Lazarus, R.S. (1991). Psychological stress in the workplace. In P.L. Perrewé (Ed.), Handbook on job stress (pp. 1-13). Corte Madera: Select Press.

Lazarus, R.S., \& Folkman, S. (1984). Coping and adaptation. In W.D. Gentry (Ed.), Handbook of behavioral medicine (pp. 282325). New York: Guilford.

Leiter, M.P., \& Durup, J. (1996). Work, home, and in-between: A longitudinal study of spill-over. Journal of Applied Behavioral Science, 32, 29-47.

Levert, T., Lucas, M., \& Ortlepp, K. (2000). Burnout in psychiatric nurses: Contributions of the work environment and a sense of coherence. South African Journal of Psychology, 30, 36-43.

Lewis, H. (1988). Uitbrandingsindroom: Siekte van ons tyd, met 'n boodskap. RSA Verpleging, 3(4), 26-28.

Maslach, C. (1993). Burnout: A multidimensional perspective. In W.B. Schaufeli, C. Maslach \& T. Marek (Eds.), Professional burnout: Recent developments in theory and research (pp. 19-32). Washington DC: Taylor \& Francis.

Maslach, C., \& Jackson, S.E. (1986). Maslach burnout inventory (2nd edn.). Palo Alto: Consulting Psychologist Press.

Maslach, C., Schaufeli, W.B., \& Leiter, M.P. (2001). Job burnout. Annual Review of Psychology, 52, 397-422.

McElfatrick, S., Carson, J., Annett, J., Cooper, C., Holloway, F., \& Kiupers, E. (2000). Assessing coping skills in mental health nurses: Is an occupation specific measure better than a generic coping skills scale? Personality and Individual Differences, 28, 965-976.

McGrath, A., Reid, N., \& Boore, J. (2003). Occupational stress in nursing. International Journal of Nursing Studies, 40, 555-565.

McKnight, J.D., \& Glass, D.C. (1995). Perceptions of control, burnout, and depressive symptomatology: A replication and extension. Journal of Consulting and Clinical Psychology, $63,490-494$

Moos, R.H. (1994, July). Conceptual and empirical advances in stress and coping theory. Paper presented at the 23rd International Congress of Applied Psychology, Madrid, Spain.

Mostert, K., \& Rothmann, S. (2006). Work-related well-being in the South African Police Service. Journal of Criminal Justice, 34, 479-491.

Naudé, J.L.P., \& Rothmann, S. (2006). Work-related well-being of emergency workers in South Africa. South African Journal of Psychology, 36, 63-81.

Nunnally, J.C., \& Bernstein, I.H. (1994). Psychometric theory (3rd edn.). New York: McGraw-Hill.

Payne, N. (2001). Occupational stressors and coping as determinants of burnout in female hospice nurses. Journal of Advanced Nursing, 33, 396-405.

Perrewé, P.L. (1991). Handbook on job stress. Corte Madera: Select Press.

Quick, J.C., Quick, J.D., Nelson, D.L., \& Hurrell, J.J. (1997). Preventative stress management in organisations. Washington DC: American Psychological Association.

Rothmann, S. (2002, March). Burnout research in South Africa. Paper presented at the 1st South African Conference on Burnout, Potchefstroom, South Africa.

Rothmann, S., Jackson, L.T.B., \& Kruger, M.M. (2003). Burnout and job stress in a local government: The moderating effects of sense of coherence. South African Journal of Industrial Psychology, 29(4), 52-60.

Rothmann, S., \& Malan, H. (2003). Koherensiesin, selfdoeltreffendheid, lokus van beheer en uitbranding by maatskaplike werkers. South African Journal of Industrial Psychology, 29(4), 43-51.

Schaufeli, W.B., \& Bakker, A.B. (2001). Werk en welbevinden: Naar een positieve benadering in de Arbeids- en Gezondheidspsychologie [Work and wellbeing: Towards a positive occupational health psychology]. Gedrag en Organizatie, 14, 229-253.
Schaufeli, W.B., \& Bakker, A.B. (2004). Job demands, job resources, and their relationship with burnout and engagement: A multi-sample study. Journal of Organizational Behaviour, 25, 1-23.

Schaufeli, W.B., \& Buunk, A.P. (1996). Professional burnout. In M.J. Schabracq, J.A.M. Winnubst \& C.L. Cooper (Eds.) Handbook of work and health psychology (pp. 311-346). Chichester: Wiley.

Schaufeli, W.B., \& Enzmann, D. (1998). The burnout companion to study and practice: A critical analysis. London: Taylor \& Francis.

Schaufeli, W.B., \& Janczur, B. (1994). Burnout among nurses. Journal of Cross-cultural Psychology, 25, 95-112.

Schaufeli, W.B., Bakker, A.B., Hoogduin, K., Schaap, C., \& Kladler, A. (2001). On the clinical validity of the Maslach Burnout Inventory and the Burnout Measure. Psychology and Health, 16, 565-582.

Schaufeli, W.B., Salanova, M., González-Romá, V., \& Bakker, A.B. (2002). The measurement of engagement and burnout: A confirmatory factor analytic approach. Journal of Happiness Studies, 3, 71-92.

Shaughnessy, J.J., \& Zechmeister, E.B. (1997). Research methods in psychology (4th edn.). New York: McGraw-Hill.

Shirom, A. (1989). Burnout in work organizations. In C.L. Cooper \& I.T. Robertson (Eds.), International Review of Industrial and Organizational Psychology, Vol. IV (pp. 25-49). New York: Wiley.

Snellgrove, S.R. (1998). Occupational stress and job satisfaction: A comparative study of health visitors, district nurses and community psychiatric nurses. Journal of Nursing Management, 6, 97-104.

Spielberger, C.D., \& Vagg, P.R. (1999). Job stress survey: Professional manual. Odessa: Psychological Assessment Resources.

SPSS Inc. (2003). SPSS 12.0 for Windows. Chicago: SPSS

Storm, K., \& Rothmann, S. (2003). A psychometric analysis of the Maslach Burnout Inventory - General Survey in the South African Police Service. South African Journal of Psychology, 33, 219-226.

Surmann, A.T. (1999). Negative mood regulation expectancies, coping, and depressive symptoms among American nurses. Journal of Social Psychology, 139, 540-543.

Tarolli-Jager, K. (1994). Personal hardiness: Your buffer against burnout. American Journal of Nursing, 94, 71-72.

Tobin, D.L., Holroyd, K.A., Reynolds, R.V., \& Wigal, J.K. (1989). The hierarchical factor structure of the Coping Strategies Inventory. Cognitive Therapy and Research, 13, 343-361.

Trummers, G.E.R., Janssen, P.P.M., Landeweerd, A., \& Houkes, I. (2001). A comparative study of work characteristics and reactions between general and mental health nurses: A multi-sample analysis. Journal of Advanced Nursing, 36, 151162.

Van der Colff, J.J. (n.d.) Work-related well-being of registered nurses in South Africa. Unpublished doctoral thesis, North-West University, Potchefstroom, South Africa.

Van der Wateren, E. (1997). Die dinamiek van waardes, coping style en psigologiese gesondheid by 'n groep jeugdiges [The dynamics of values, coping styles and psychological strengths in a group of youths]. Unpublished master's thesis, PU for CHE, Potchefstroom, South Africa.

Wissing, M.P., De Waal, M., \& De Beer, I. (1992, July). Sense of coherence and stress symptomatology. Paper presented at the 25th International Congress of Psychology, Brussels, Belgium.

Wright, L.A., \& Smye, M.D. (1996). Corporate abuse: How lean and mean robs people and profits. New York: Macmillan.

Zeidner, M., \& Endler, N.S. (1996). Handbook of coping: Theory, research, applications. New York: Wiley. 